\title{
Prática desportiva de estudantes universitários: o caso da Universidade do Porto
}

\author{
Nuno Corte-Real \\ Cláudia Dias \\ Rui Corredeira \\ André Barreiros \\ Tânia Bastos \\ António Manuel Fonseca
}

\author{
Universidade do Porto \\ Faculdade de Desporto \\ Portugal
}

\section{RESUMO}

Embora as vantagens associadas à prática desportiva por pessoas de todas as idades sejam hoje perfeitamente evidentes, vários estudos realizados com populações universitárias têm destacado o seu elevado sedentarismo, razão pela qual se justifica investigar as determinantes da sua actividade desportiva. Reconhecendo a importância assumida neste domínio pelas dimensões social, cognitiva e afectiva, este estudo procurou analisar a prática desportiva de estudantes universitários, relacionando-a com variáveis intrapessoais (e.g., sexo, idade) e interpessoais (e.g., hábitos desportivos de familiares e amigos). Participaram 2284 estudantes dos dois sexos, com idades entre os 18 e os 30 anos (média \pm desvio-padrão $=21.87 \pm 2.37$ ), que preencheram um questionário sobre a sua prática desportiva e a dos seus familiares e amigos. A análise dos resultados evidenciou que os estudantes: i) preferiam actividades de fitness, natação e futebol, bem como actividades menos tradicionais (e.g., capoeira); ii) praticavam maioritariamente desporto recreativo, ao longo de todo o ano, em associações/ academias/ ginásios; iii) os homens eram mais activos; iv) maioritariamente preferiam praticar desporto acompanhados, o que convergia com as correlações positivas encontradas entre a regularidade da sua prática e a dos seus amigos e familiares. Daqui resulta, portanto, a importância de adequar a oferta desportiva às preferências dos estudantes, não só em termos de modalidades e espaços, mas também considerando o papel dos outros significativos.

Palavras-chave: estudantes universitários, prática desportiva, influências sociais

\section{ABSTRACT \\ Sport practice of university students: the case of the University of Porto}

Despite the clear benefits associated to sport practice to people of all ages, some studies with university students have shown high prevalence of sedentary habits, reason why it is important to investigate the determinants of their sport participation. Considering the importance in this domain of social, cognitive and affective dimensions, this study analysed sport practice of university students in relation with intrapersonal (e.g., sex, age) and interpersonal (e.g. relatives and friends sport habits) variables. Participated in this investigation 2284 male and female students, aged between 18 and 30 years (mean \pm standard deviation $=21.87 \pm 2.37$ ), who filled out a questionnaire to assess their levels of sport practice, as well as their relatives and friends sport habits. Overall, results showed the students: i) preferred to practice fitness, swimming and soccer, as well as traditional activities (e.g., capoeira); ii) preferred to practice sport recreationally, all year long, in associations/ academies/ gymnasia; iii) men were more active; iv) preferred to practice sport in group, which is consistent with the positive correlations found between the students' regular sport practice and their relatives' and friends' sport habits. Therefore, these results suggest the importance of matching the sport offer to the preferences of students, not only in relation to activities and places, but also considering the role of significant others.

Key-words: university students, sport practice, social influences 


\section{INTRODUÇÃO}

A concepção do que são estilos de vida saudáveis tem vindo a evoluir ao longo das últimas décadas, parecendo, de certa forma, acompanhar a evolução da própria sociedade. Esta evolução é expressa, por exemplo, na mudança do foco de interesse dos investigadores neste domínio, que, classicamente, privilegiavam o estudo do consumo de álcool, consumo de tabaco, hábitos alimentares e hábitos de actividade física, e, nos últimos anos, se começaram a interessar por outros comportamentos, como o consumo de drogas e medicamentos, acidentes e comportamentos de risco, higiene dental, frequência de realização de exames médicos, actividades desenvolvidas nos tempos livres, comportamentos sexuais ou cuidados com a aparência e higiene(1).

No entanto, apesar de toda a evolução verificada e não obstante não ser completamente consensual o conceito de estilo de vida saudável - perdurando algumas confusões terminológicas e mesmo conceptuais - a actividade física constitui-se, indubitavelmente, como uma das componentes com mais peso na definição do mesmo, existindo uma convicção cada vez mais forte das vantagens físicas, psicológicas e sociais aliadas à sua prática, em todas as idades, quer por parte da população em geral, quer ao nível da comunidade científica.

Este reconhecimento dos benefícios da prática de actividade física não evita, porém, que o número de pessoas sedentárias seja extremamente elevado. De facto, um estudo realizado a nível europeu e apresentado pela Organização Mundial de Saúde em 2002 revelou que $41 \%$ da população não era suficientemente activa para daí retirar benefícios para a sua saúde; essa investigação concluiu também que, em Portugal, 70\% dos indivíduos não eram fisicamente activos ${ }^{(2)}$. De forma semelhante, nos Estados Unidos, de acordo com um relatório do United States Department of Health and Human Services de 1996 (3), $60 \%$ das pessoas não participavam nem realizavam actividade física de forma suficientemente regular para usufruírem dos benefícios inerentes à mesma; agravando esta situação, existem evidências de que aproximadamente $50 \%$ dos adultos que começam um programa de actividade física o abandonam entre o terceiro e o sexto mês(4).
Paralelamente, os dados disponíveis até ao momento mostram que a prática de actividade física diminui com a idade, existindo uma diminuição mais acentuada no final da adolescência (entre os 15 e os 18 anos)(22, 25), e início da idade adulta (entre os 20 e os 25 anos) ${ }^{(5,3)}$, altura em que se fixam comportamentos de sedentarismo ${ }^{(6)}$. Corroborando esses dados, uma investigação realizada em 1994 por Calfas, Sallis, Lovato e Campbell(7) revelou que $47 \%$ dos estudantes norte-americanos diminuíam os níveis de actividade física quando entravam na universidade e estudos recentes em universidades espanholas apontaram no sentido de um elevado sedentarismo por parte da comunidade universitária $(8,9)$.

Desta forma, considerando, por um lado, que a maioria dos jovens não cumpre as recomendações de saúde pública no sentido da manutenção de uma actividade física regular e sistemática(3) e, por outro lado, que a adopção de comportamentos protectores de saúde na infância, adolescência e início da idade adulta, pode determinar a qualidade da vida adulta e velhice $^{(10,11)}$, o desenvolvimento de hábitos de actividade física deve constituir um dos principais objectivos das políticas de educação para a saúde. Urge portanto proceder à definição e implementação de medidas rápidas e eficazes neste domínio, que promovam o desenvolvimento de atitudes positivas e hábitos de actividade física que se possam enquadrar na vida quotidiana.

No entanto, promover a adopção regular de práticas de actividade física e a sua manutenção ao longo do tempo constitui um desafio, tanto para as instituições, como para os diferentes profissionais implicados neste processo. No caso específico dos estudantes universitários tal desafio pode ser ainda maior, na medida em que, de uma forma geral e para se manterem fisicamente activos quando ingressam no ensino superior, os jovens terão que desenvolver os seus próprios programas de exercício físico, ao mesmo tempo que enfrentam numerosos e novos obstáculos (e.g., novas carreiras, novas "famílias", menos acesso a actividades de grupo, programas e instalações; necessidade de dedicarem mais tempo aos estudos). Para além disso, apesar de os campus universitários constituírem - ou poderem constituir - um ambiente único, em que esforços de informa- 
ção e promoção da actividade física e desportiva podem abranger um vasto número de jovens adultos antes de estes entrarem no mercado de trabalho(12), de uma forma geral, os estudantes universitários não parecem estar preparados de forma eficaz para a transição para uma actividade física que deixa de ser obrigatória e passa a ser voluntária(13).

Assim, para desenvolver atitudes positivas e hábitos de actividade física que se possam enquadrar na vida quotidiana dos estudantes universitários, é fundamental não só conhecer a realidade a que nos estamos a referir, mas também apreender a natureza multifacetada que está inerente a um estilo de vida fisicamente activo, que ultrapassa largamente uma dimensão físico-comportamental, envolvendo também uma dimensão, cognitiva, afectiva e social. Neste contexto, importa considerar a socialização na adopção e manutenção de estilos de vida saudáveis, entre os quais um estilo de vida activo $(14,15,16)$, razão pela qual é indispensável uma exploração mais aprofundada das influências sociais na actividade física ou ausência de actividade física - dos jovens.

De facto, é no processo de socialização que se aprendem determinados comportamentos, valores e atitudes das pessoas mais próximas - incluindo pais, familiares, amigos e/ ou outras pessoas significativas - sendo nesse processo abrangidos os comportamentos e atitudes que respeitam à participação na actividade física, no sentido de a reforçar ou inibir $(17,18)$. Seguindo o mesmo raciocínio, há motivos para acreditar que, se os amigos ou a família atribuem um escasso valor à actividade física, os jovens também darão pouco valor e importância à participação neste tipo de actividades(19); por outro lado, quando aqueles estão ou já estiveram envolvidos no desporto, há uma maior probabilidade dos jovens também serem fisicamente activos(20).

Decorrendo do exposto, porque os dados actualmente disponíveis neste domínio do conhecimento, particularmente no que concerne ao nosso país, são ainda escassos, e partindo do princípio que para modificar uma realidade como aquela a que nos temos vindo a referir é fundamental que, para além da sua descrição, possuamos algum conhecimento sobre o que lhe está na origem e o que a determina e condiciona, urge não só caracterizar os hábitos de actividade física dos jovens universitários, mas tam- bém explorar o padrão de inter-relações entre o seu envolvimento na actividade física e o carácter relacional que rodeia esse envolvimento, ou seja, os hábitos de actividade física dos familiares e amigos. Tal poderá constituir-se como um aspecto fundamental na contribuição para a identificação de soluções e implementação de estratégias de mudança, no sentido de tentar que os estilos de vida activos se mantenham durante toda a vida.

Porém, a actividade física pode englobar, entre outras, actividades tão diversas como as mais quotidianas (e.g., andar, tarefas domésticas), actividades cíclicas (e.g., andar, correr, saltar à corda), exercícios de preparação física (e.g., flexões de braços, estiramentos), ou a prática de desportos(21), o que torna este conceito de difícil avaliação na sua totalidade(22). Nesta medida, optou-se por considerar nesta investigação apenas a prática desportiva, incluindo nesta definição todas as formas de actividade física que, através de uma participação organizada ou não, têm por objectivo a melhoria da condição física e psíquica, o desenvolvimento das relações sociais ou a obtenção de resultados em competições de todos os níveis (23). Ou seja, esta definição implica não só a intencionalidade do indivíduo para adoptar estes comportamentos, mas também um certo grau de regularidade, tornando o estudo da prática desportiva dos estudantes universitários uma questão relevante se o que pretendemos é desenvolver estratégias e encontrar soluções para facilitar um estilo de vida activo e saudável neste contexto específico. Decorrendo do exposto, com este estudo procurouse examinar a prática desportiva de estudantes universitários, bem como o modo como a referida prática desportiva se relacionava com variáveis de natureza intrapessoal (e.g., sexo, idade) e interpessoal (e.g., hábitos desportivos dos familiares e amigos) dos estudantes.

\section{MATERIAL E MÉTODOS}

\section{Amostra}

A amostra foi constituída por 2284 estudantes de licenciatura, pós-graduação, mestrado e doutoramento ( $29.3 \%$ do sexo masculino e $70.7 \%$ do sexo feminino) da Universidade do Porto, a maior universidade portuguesa, com idades compreendidas entre os 18 e os 30 anos (média \pm desvio-padrão $=21.87 \pm 2.37$ ). 


\section{Instrumento e Procedimentos}

Os dados foram recolhidos no âmbito de um estudo mais vasto sobre os hábitos desportivos dos estudantes, docentes e funcionários não docentes da Universidade do Porto, para o Instituto de Recursos e Iniciativas desta Universidade, o qual contou com a autorização dos Conselhos Directivos e a colaboração dos docentes das diversas faculdades na administração dos questionários.

Para este estudo foi desenvolvido o "Inventário dos Hábitos Desportivos na Universidade do Porto" (2006), o qual avaliava não só a prática desportiva efectuada pelos estudantes, mas também o envolvimento e carácter relacional da mesma.

Num primeiro momento, os sujeitos deveriam indicar a frequência (1 a 3 vezes/ mês, 1 vez/ mês, 2 a 3 vezes/semana, 4 a 5 vezes/semana, 6 a 7 vezes/ semana) e duração habitual (menos de 20 minutos, entre 20 e 45 minutos, mais de 45 minutos) de cada sessão de treino, das três modalidades mais praticadas. Com base nas suas respostas foram constituídos três grupos de estudantes com níveis distintos de prática desportiva: i) inexistente, ii) irregular (no máximo 2 a 3 vezes/ semana, menos de 20 minutos); e iii) regular (pelo menos 2 a 3 vezes/ semana, mais de 20 minutos/sessão).

Em relação ao envolvimento e carácter relacional da prática desportiva dos estudantes, num primeiro momento, foi-lhes perguntado com quem é que praticavam normalmente desporto; de seguida, deveriam indicar com quem praticavam quando o faziam acompanhados. Paralelamente, foram questionados quanto aos hábitos desportivos do grupo habitual de colegas da faculdade e do grupo habitual de amigos fora da faculdade, assim como dos pais, irmãos(ãs) mais velhos(as) e mais novos(as) e melhores amigos e amigas, devendo referir a frequência com que as pessoas abrangidas nesses grupos praticava desporto.

No tratamento estatístico, para além dos dados de estatística descritiva (frequência e percentagem), recorremos, ainda, ao teste do qui-quadrado $\left(\chi^{2}\right)$ para explorar diferenças a vários níveis nos hábitos de prática desportiva dos estudantes, e, por último, ao coeficiente de Pearson (r) para relacionar os índices de prática desportiva dos estudantes e os hábitos desportivos dos seus familiares e amigos.

\section{RESULTADOS}

Que prática desportiva?

A análise dos dados relativos à frequência e duração de prática desportiva dos estudantes da Universidade do Porto envolvidos neste estudo revelou que quase metade dos sujeitos (47\%) não praticava qualquer tipo de actividade; ainda assim, cerca de $40 \%$ dos estudantes estavam envolvidos numa prática desportiva regular e frequente (Quadro 1).

Quadro 1. Frequência e duração da prática desportiva dos estudantes universitários. Análise da amostra global.

\begin{tabular}{lc}
\hline Frequência e duração da prática desportiva & $\%$ \\
\hline PD inexistente & 47.1 \\
\hline PD reduzida & 13.3 \\
\hline PD regular & 39.6 \\
\hline TOTAL & 100 \\
\hline
\end{tabular}

Relativamente às modalidades mais praticadas, os estudantes pareciam preferir, por ordem decrescente, actividades de fitness, natação e futebol - correspondendo a praticamente $50 \%$ das modalidades apontadas como preferências. Além disso, refira-se o elevado número de estudantes envolvido em "outras actividades", entre as quais se incluíam a capoeira, o snowboard, o snooker, o pólo aquático ou o remo/ canoagem (Quadro 2).

Quadro 2. Modalidades mais citadas pelos estudantes universitários. Análise da amostra global. ${ }^{1}$

\begin{tabular}{lclc}
\hline Modalidades & $\%$ & Modalidades & $\%$ \\
\hline Fitness & 28.9 & Patinagem & 3.1 \\
\hline Natação & 11.7 & Basquetebol & 3.1 \\
\hline Futebol & 10.7 & Artes marciais & 2.7 \\
\hline Desportos de raquete & 5.2 & Ginástica & 2 \\
\hline Atletismo & 4.5 & Desportos motorizados & .8 \\
\hline Ciclismo & 4.2 & Hóquei em patins & .7 \\
\hline Montanhismo & 3.3 & Equitação & .5 \\
\hline Voleibol & 3.2 & Outras modalidades & 10.5 \\
\hline Andebol & 3.1 & TOTAL & 100 \\
\hline Surf & 3.1 & &
\end{tabular}

Quanto ao tipo, a prática desportiva dos estudantes parecia ter um cariz essencialmente recreativo existindo, um número relativamente escasso de estudantes envolvidos no desporto federado e/ ou universitário; com efeito, enquanto $80 \%$ dos estudantes pra- 
Quadro 3. Tipo, local habitual e época do ano de prática das modalidades mais praticadas pelos estudantes universitários. Análise da amostra global.

\begin{tabular}{lclclc}
\hline Tipo de prática desportiva & $\%$ & Local de prática desportiva & $\%$ & Época do ano de prática desportiva & $\%$ \\
\hline Recreativa & 80.4 & Clube desportivo & 14.9 & Todo o ano & 68.4 \\
\hline Federada & 11.3 & Instalaçães universitárias & 14.6 & Mais no Verão & 22.8 \\
\hline Desporto universitário & 8.3 & $\begin{array}{l}\text { Associação/Academia/ } \\
\text { Ginásio }\end{array}$ & 33 & Mais no Inverno & 8.8 \\
\hline TOTAL & 100 & $\begin{array}{l}\text { Outro local } \\
\text { (não especificado) }\end{array}$ & 34.5 & TOTAL & 100 \\
\hline & Vários locais e não apenas um & 3 & & 100 \\
\hline
\end{tabular}

ticava desporto recreativo, só $11 \%$ dos sujeitos referiram praticar desporto federado e apenas $8 \%$ assinalaram o desporto universitário.

No que respeita aos locais onde se processava a prática, verificou-se que, não obstante terem oportunidade de praticar desporto na própria universidade graças a diversas instalações disponibilizadas para o efeito, os espaços mais utilizados pela generalidade dos estudantes eram locais não identificados (35\%) e associações/ academias/ ginásios (33\%). Por fim, a análise da época do ano preferida para a prática de desporto revelou que a maior parte dos sujeitos $(68 \%)$ o fazia todo o ano, sendo o Inverno a época do ano menos escolhida (9\%) (Quadro 3).

Quando analisámos o envolvimento e carácter relacional da prática desportiva, constatámos que a maior parte dos estudantes (53\%) afirmou que o mais usual era a prática em grupo, sendo que, quando o faziam em parceria, a companhia preferida era, claramente, a dos amigos de fora da faculdade (66\%) (Quadro 4).

Quadro 4. Envolvimento dos estudantes universitários na prática desportiva. Análise da amostra global.

Normalmente, com quem pratica desporto?

\begin{tabular}{lc}
\hline Sozinho(a), a maior parte das vezes & 17.8 \\
Umas vezes sozinho(a), outras em grupo & 29.5 \\
Normalmente em grupo & 52.7 \\
TOTAL & 100 \\
\hline Quando pratica acompanhado[a], com quem o faz? & \\
\hline Grupos de amigos que não são colegas da faculdade & 66.2 \\
Grupo de amigos da faculdade & 18.7 \\
Familiares & 15.1 \\
TOTAL & 100 \\
\hline
\end{tabular}

Relativamente aos hábitos desportivos dos seus amigos da faculdade e de fora da faculdade, um elevado número de estudantes afirmou que estes nunca ou raramente praticavam desporto. Na verdade, apenas um em cada quatro dos estudantes referiu que os seus amigos da faculdade praticavam desporto frequentemente, aumentando um pouco essa proporção quando considerados os amigos de fora da faculdade (ver Quadro 5).

Quadro 5. Hábitos desportivos dos amigos da faculdade e de fora da faculdade dos estudantes universitários. Análise da amostra global.

\begin{tabular}{lcc}
\hline Hábitos desportivos & $\begin{array}{c}\text { Grupo habitual } \\
\text { de colegas } \\
\text { da faculdade }\end{array}$ & $\begin{array}{c}\text { Grupo habitual } \\
\text { de amigos fora } \\
\text { da faculdade }\end{array}$ \\
\hline A maioria nunca pratica & 21.2 & $\%$ \\
\hline A maioria raramente pratica & 53.6 & 13.9 \\
\hline A maioria pratica frequentemente & 25.2 & 48.8 \\
\hline TOTAL & 100 & 37.3 \\
\hline
\end{tabular}

Todavia, quando considerados apenas o melhor amigo (amiga), verificou-se que a percentagem dos que praticavam frequentemente era claramente superior, em especial no que se refere ao melhor amigo (cerca de 60\%). Na verdade, no caso da melhor amiga o valor era relativamente mais baixo, com $40 \%$ dos estudantes a indicarem uma prática rara e $40 \%$ uma prática frequente (Quadro 6). 
Quadro 6. Hábitos desportivos do melhor amigo e melhor amiga dos estudantes universitários. Análise da amostra global.

\begin{tabular}{lcc}
\hline Hábitos desportivos & Melhor amigo & Melhor amiga \\
\hline Nunca & $\%$ & $\%$ \\
\hline Raramente & 11.4 & 18.3 \\
\hline Frequentemente & 28.2 & 40.5 \\
\hline TOTAL & 60.4 & 41.2 \\
\hline
\end{tabular}

Por último, os hábitos desportivos dos pais apontavam claramente no sentido do sedentarismo, porquanto menos de um em cada quatro estudantes referiu que o pai e a mãe praticavam desporto frequentemente. Porém, os hábitos do irmão(ã) mais velho(a) e do irmão(ã) mais novo(a) pareciam ser substancialmente diferentes: enquanto no caso do(a) irmão(ã) mais velho(a), 47\% dos estudantes afirmaram que a prática desportiva era frequente, no que concerne o(a) irmão(ã) mais novo(a) essa percentagem aumentava para os 64\% (Quadro 7).

\begin{tabular}{|c|c|c|c|c|}
\hline $\begin{array}{l}\text { Hábitos } \\
\text { desportivos }\end{array}$ & Pai & Mãe & $\begin{array}{l}\text { Irmão[ã] } \\
+ \text { velho[a] }\end{array}$ & $\begin{array}{l}\text { Irmão[ã) } \\
+ \text { novo(a) }\end{array}$ \\
\hline & $\%$ & $\%$ & $\%$ & $\%$ \\
\hline Nunca & 43.8 & 50.4 & 21.2 & 14.9 \\
\hline Raramente & 32.5 & 29.0 & 32.1 & 21.2 \\
\hline Frequentemente & 23.8 & 20.7 & 46.8 & 63.9 \\
\hline TOTAL & 100 & 100 & 100 & 100 \\
\hline
\end{tabular}

\section{Prática Desportiva: Que diferenças e que relações?}

A análise comparativa da frequência e duração da prática desportiva dos estudantes em função do sexo (ver Quadro 8) revelou que os homens tinham uma prática significativamente mais elevada do que as mulheres $\left(\chi_{(2)}^{2}=124.20, \mathrm{p}<.001\right)$.

Quadro 8. Frequência e duração da prática desportiva dos estudantes universitários. Análise em função do sexo.

\begin{tabular}{lcc}
\hline $\begin{array}{l}\text { Frequência e duração } \\
\text { da prática desportiva }\end{array}$ & $\begin{array}{c}\text { Sexo } \\
\text { masculino }\end{array}$ & $\begin{array}{c}\text { Sexo } \\
\text { feminino }\end{array}$ \\
\hline PD inexistente & $\%$ & $\%$ \\
\hline PD reduzida & 28.8 & 54.7 \\
\hline PD regular & 16.9 & 11.6 \\
\hline TOTAL & 54.2 & 33.7 \\
\hline & 100 & 100 \\
\hline
\end{tabular}

Ao invés, quando procedemos à análise da prática desportiva realizada pelos estudantes em função da sua idade (ver Quadro 9) não se verificaram quaisquer diferenças estatisticamente significativas, quer no sexo masculino $\left(\chi^{2}{ }_{(4)}=1.43, \mathrm{p}>.05\right)$ quer no feminino $\left(\chi^{2}{ }_{(4)}=3.84, \mathrm{p}>.05\right)$. Todavia, encontrámos uma ligeira diminuição da prática desportiva regular nos estudantes do sexo masculino, enquanto que no sexo feminino ocorria o oposto.

Quando procurámos verificar se os estudantes que realizavam a sua prática desportiva acompanhados se distinguiam relativamente aos que a realizavam sozinhos, em termos da frequência e duração dessa mesma prática (ver Quadro 10), verificámos que a diferença não atingia significado estatístico $\left(\chi^{2}(2)=4.03, \mathrm{p}>.05\right)$.

Todavia, considerando apenas os dados relativos aos que praticavam desporto acompanhados em função do tipo de companhia (i.e., se ela era desenvolvida com amigos da faculdade, amigos de fora da faculdade ou familiares), foram identificadas diferenças estatisticamente significativas $\left(\chi^{2}{ }_{(2)}=10.54, \mathrm{p}<.01\right)$. $\mathrm{Na}$ verdade, foi possível verificar que os estudantes que praticavam desporto com amigos (da faculdade ou de fora da faculdade) o faziam de forma mais regular do que aqueles que o faziam com familiares, sendo a diferença mais evidente quando considerados os amigos da faculdade (Quadro 11).

No mesmo sentido, quando se procurou analisar a relação entre a prática desportiva realizada pelos estudantes e a prática desportiva que os seus familiares e amigos realizavam (Quadro 12), encontraram-se correlações positivas estatisticamente significativas entre todas as variáveis envolvidas na análise, revelando que hábitos desportivos mais regulares por parte dos familiares e amigos mais próximos estavam associados positivamente a uma prática mais regular da sua parte; de referir, a este propósito que, na linha dos dados anteriormente analisados, essa associação revelou ser mais forte relativamente aos hábitos desportivos do melhor amigo ou amiga do que em relação aos dos familiares.

\section{DISCUSSÃO E CONCLUSÕES}

A prática de actividade física ou desportiva, de carácter recreativo ou mesmo realizada num contexto mais competitivo, tem tido, nos últimos anos, um 
Quadro 9. Frequência e duração da prática desportiva dos estudantes universitários. Análise em função da idade.

\begin{tabular}{|c|c|c|c|c|c|c|}
\hline \multirow{2}{*}{$\begin{array}{l}\text { Frequência e duração } \\
\text { da prática desportiva }\end{array}$} & \multicolumn{3}{|c|}{ Sexo Masculino } & \multicolumn{3}{|c|}{ Sexo Feminino } \\
\hline & $18-20$ anos & $21-23$ anos & $24-30$ anos & $18-20$ anos & $21-23$ anos & $24-30$ anos \\
\hline & $\%$ & $\%$ & $\%$ & $\%$ & $\%$ & $\%$ \\
\hline PD inexistente & 26.7 & 28.1 & 31.5 & 54.5 & 54.7 & 54.7 \\
\hline$\underline{\mathrm{PD} \text { reduzida }}$ & 14.4 & 16.1 & 15.8 & 13.0 & 11.1 & 8.5 \\
\hline$\underline{\mathrm{PD} \text { regular }}$ & 58.9 & 55.8 & 52.7 & 32.6 & 34.2 & 36.8 \\
\hline \multirow[t]{2}{*}{ TOTAL } & 100 & 100 & 100 & 100 & 100 & 100 \\
\hline & \multicolumn{3}{|c|}{$\chi^{2}(4)=1.43, p>.05$} & \multicolumn{3}{|c|}{$\chi^{2}(4)=3.84, p>.05$} \\
\hline
\end{tabular}

Quadro 10. Frequência e duração da prática desportiva dos estudantes universitários. Análise em função de prática isolada ou acompanhada.

\begin{tabular}{|c|c|c|c|}
\hline \multirow[b]{2}{*}{$\begin{array}{l}\text { Frequência e duração } \\
\text { da prática desportiva }\end{array}$} & \multicolumn{3}{|c|}{ Normalmente, com quem pratica desporto? } \\
\hline & $\begin{array}{l}\text { Sozinho(a), a maior } \\
\text { parte das vezes }\end{array}$ & $\begin{array}{c}\text { Umas vezes sozinho[a], } \\
\text { outras em grupo }\end{array}$ & $\begin{array}{c}\text { Normalmente } \\
\text { em grupo }\end{array}$ \\
\hline & $\%$ & $\%$ & $\%$ \\
\hline PD reduzida & 25.6 & 28 & 22.2 \\
\hline PD regular & 74.4 & 72 & 77.8 \\
\hline \multirow[t]{2}{*}{ TOTAL } & 100 & 100 & 100 \\
\hline & & $\chi^{2}(2)=4.03, p>.05$ & \\
\hline
\end{tabular}

Quadro 11. Frequência e duração da prática desportiva dos estudantes universitários. Análise em função do tipo de prática acompanhada.

\begin{tabular}{|c|c|c|c|}
\hline \multirow[b]{2}{*}{$\begin{array}{l}\text { Frequência e duração } \\
\text { da prática desportiva }\end{array}$} & \multicolumn{3}{|c|}{ Quando pratica acompanhado[a], com quem o faz?? } \\
\hline & $\begin{array}{l}\text { Grupo de amigos } \\
\text { de fora da faculdade }\end{array}$ & $\begin{array}{l}\text { Grupo de amigos } \\
\text { da faculdade }\end{array}$ & Familiares \\
\hline & $\%$ & $\%$ & $\%$ \\
\hline PD reduzida & 24.8 & 18.6 & 34.5 \\
\hline PD regular & 75.2 & 81.4 & 65.6 \\
\hline \multirow[t]{2}{*}{ TOTAL } & 100 & 100 & 100 \\
\hline & & $2[2]=10.538, p<$. & \\
\hline
\end{tabular}

Quadro 12. Correlações dos hábitos desportivos dos familiares e amigos dos estudantes com a frequência e duração da de prática desportiva dos estudantes. Análise da amostra global.

\begin{tabular}{|c|c|}
\hline & Prática desportiva dos estudantes \\
\hline Hábitos desportivos do pai & $.14^{* *}$ \\
\hline Hábitos desportivos da mãe & $.14^{* *}$ \\
\hline Hábitos desportivos do irmão(ã) mais velho(a) & $.15^{* *}$ \\
\hline Hábitos desportivos do irmão[ã] mais novo[a] & $.10^{*}$ \\
\hline Hábitos desportivos do melhor amigo & $.22^{* *}$ \\
\hline Hábitos desportivos da melhor amiga & $.24^{* *}$ \\
\hline Hábitos desportivos do grupo habitual de colegas da faculdade & $.22^{* *}$ \\
\hline Hábitos desportivos do grupo habitual de amigos fora da faculdade & $.26^{* *}$ \\
\hline$*_{p}<.01 ; * * p<.001$ & \\
\hline
\end{tabular}


reconhecimento crescente na promoção da saúde e na prevenção da doença, podendo mesmo considerar-se um dos principais indicadores de saúde.

Contudo, ainda que seja do conhecimento geral que a actividade física e, dentro desta, a prática desportiva, proporciona múltiplos benefícios nos domínios físico e psicológico, existem características pessoais (funcionais ou psicológicas; e.g., idade, sexo, atitudes, crenças, personalidade) e contextuais (sociais ou estruturais; e.g., existência de oportunidades para a prática, motivação e história de prática na infância, apoio e incentivo paterno, apoio de outros significativos, transportes aos locais, custos), que condicionam a sua adopção e manutenção no tempo (24). No caso dos estudantes universitários, a acrescer a estes factores, importa ter em consideração que durante o período em que decorre a vida universitária, aqueles são expostos a uma série de obstáculos e impedimentos à prática desportiva, que, em última análise, tornam a Universidade e os seus órgãos de gestão responsáveis pelo desenvolvimento e promoção de condições para a prática de actividade física e desportiva. No entanto, para que se possam desenvolver intervenções eficazes, é necessário compreender a realidade desportiva universitária e caracterizála nos seus pormenores e inter-relações, razões subjacentes à realização desta investigação.

Da análise dos nossos dados resultou que, de entre as modalidades desportivas mais praticadas pelos estudantes, se situavam modalidades ditas mais "tradicionais", como a natação, o futebol ou o fitness; embora também fosse possível verificar a atracção dos estudantes pela prática de outro tipo de modalidades mais contemporâneas ou, pelo menos, cujo destaque social é mais recente, como sejam, por exemplo, a capoeira ou o snowboard. Foi ainda evidente que a prática desportiva da esmagadora maioria dos estudantes que participaram no presente estudo era essencialmente recreativa, ocorrendo ao longo de todo o ano em instalações exteriores à Universidade.

De uma forma geral, todos estes dados estão em consonância com os de diversas investigações realizadas igualmente com populações universitárias, nomeadamente em Espanha (ver ref's 8, 9) e nos Estados Unidos da América (e.g., 7), as quais revelaram que a natação, o futebol e as actividades de manutenção e fitness eram as actividades mais praticadas pelos estudantes, durante todo o ano, não se constituindo as instalações universitárias como o local privilegiado pelos estudantes para a sua realização.

Aproximadamente metade dos estudantes não realizava qualquer tipo de prática desportiva. Sendo esta percentagem muito superior ao que se poderia eventualmente aceitar como natural, importará destacar que ela converge com o que tem vindo a ser reportado noutras investigações, nacionais e internacionais, desenvolvidas com crianças, adolescentes e adultos(e.g., 4, 5, 6, 22, 25), bem como com estudantes universitários norte-americanos (e.g., 7) e espanhóis(e.g., $8,9)$, as quais têm revelado igualmente elevadas taxas de inactividade por parte das populações estudadas. A comparação da prática desportiva realizada por indivíduos dos dois sexos permitiu identificar uma maior inactividade por parte das mulheres.

Relativamente à idade, embora as diferenças não fossem significativas em nenhum dos sexos, foi possível constatar uma tendência para a diminuição da prática desportiva regular, no sexo masculino, com a idade. Estes resultados, sendo consistentes com o que tem vindo a ser encontrado em diversos estudos realizados em Portugal (e.g., 22, 25) e no estrangeiro (e.g., 3, 5, 9, 14, 26, 27), designadamente no que se refere aos indivíduos do sexo masculino serem fisicamente mais activos, em qualquer idade, parecem fornecer suporte para a noção tradicional de género, segundo a qual os rapazes são mais incentivados, por exemplo, por pais e outros significativos, para praticarem desporto, enquanto relativamente às raparigas o estímulo para um estilo de vida fisicamente activo é menos notório e frequente. No entanto, a ligeira tendência verificada no nosso estudo para um aumento com a idade, da regularidade da prática desportiva nas mulheres, poderá estar relacionada com uma crescente preocupação com questões relacionadas com a sua saúde à medida que vão ficando mais velhas.

No que concerne à possível intervenção a realizar neste domínio, atendendo à importância de um estilo de vida fisicamente activo e ao reconhecimento de que os estudantes universitários estão numa fase da vida particularmente susceptível a desafios e "tentações" mais associados ao sedentarismo do que a uma prática desportiva regular, importará 
sublinhar a necessidade de os programas de promoção da actividade física e desportiva para esta população se constituírem como suficientemente apelativos, "seduzindo-os" para as vantagens de praticarem desporto.

Neste sentido, será importante flexibilizar a oferta desportiva, no sentido de corresponder às exigências e interesses alargados dos estudantes universitários, nomeadamente no que respeita ao seu interesse por modalidades menos tradicionais. Para além disso, e recordando a habitualmente escassa utilização das instalações desportivas universitárias, poderá revelar-se como útil, para a referida sedução dos estudantes para a prática desportiva, a divulgação e/ ou melhoria das condições das instalações actualmente existentes. Na verdade, esta tentativa de ajustamento das características da oferta às necessidades e desejos dos estudantes deverá considerar - para além do tipo de modalidades disponíveis - diversos factores potencialmente condicionantes da escolha dos estudantes relativamente ao modo e local da sua prática desportiva, como sejam, por exemplo, a acessibilidade e a qualidade dos espaços, a qualidade das actividades, a qualidade do pessoal, o preço ou a publicidade.

Paralelamente, foi também possível constatar que a maior parte dos estudantes envolvidos neste estudo gostava mais de praticar desporto em grupo, preferencialmente com amigos, do que isoladamente, o que converge com as associações positivas encontradas entre a frequência e duração da prática desportiva dos estudantes e a dos seus amigos e familiares. Estes resultados são similares aos obtidos por Sanz em 2005(9), numa investigação com os membros da comunidade universitária espanhola, os quais também declararam preferir praticar desporto acompanhados, essencialmente por amigos mas também, embora menos frequentemente, por familiares. A questão, porém, é que uma percentagem muito elevada dos estudantes envolvidos no presente estudo declarou que, de uma forma geral, os seus amigos raramente praticavam desporto, sendo ainda mais os que referiram que os hábitos de prática desportiva dos seus familiares eram muito reduzidos ou mesmo inexistentes.

Ora, as influências sociais, nomeadamente a influência combinada de pais e "outros significativos", são determinantes importantes para a actividade física dos jovens(16), existindo evidências de que, se a família ou amigos atribuem um escasso valor à actividade física, os jovens também o farão(19). Logo, o facto dos estudantes do presente estudo preferirem praticar desporto acompanhados, mas os seus amigos e familiares não praticarem, ou praticarem de forma irregular, poderá constituir-se como facilitador da irregularidade e inconsistência do seu próprio envolvimento no desporto.

Neste sentido, poderá ser importante que os órgãos de gestão responsáveis pela promoção da prática desportiva dos universitários equacionem a possibilidade de permitir que os estudantes realizem a sua prática desportiva conjuntamente com outras pessoas, mesmo que não sejam elementos da comunidade académica.

Em suma, o presente estudo forneceu apoio para a noção de que é urgente intervir ao nível da promoção de condições que possibilitem que os estudantes adoptem um estilo de vida fisicamente activo ao longo do seu percurso universitário. Para tal importa definir e implementar estratégias que passem não só pelo investimento em aspectos de natureza estrutural (mais associados à questão das instalações onde poderá realizar-se a referida prática desportiva ou o tipo de actividades disponibilizadas) mas também noutro tipo de aspectos, como sejam os que se referem a questões de natureza relacional, isto é, mais centradas com quem e como se poderá realizar a prática desportiva dos estudantes universitários.

\section{NOTAS}

${ }^{1}$ As modalidades foram agrupadas, de forma a facilitar a leitura do Quadro. Assim: Ciclismo - BTT; Artes marciais - karate, judo, ...; Futebol - de 11, de 5, futsal; Ginástica - artística, ballet, ...; Montanhismo - escalada, caminhadas, orientação, ...; Patinagem - skate,...; D. raquete - ténis, ténis de mesa, badmington,...; Surf - bodyboard, windsurf, vela,...; fitness - ginásticas de academia: musculação, aeróbica, step, dança,...hidroginástica

\section{CORRESPONDÊNCIA}

\section{Nuno Corte-Real}

Faculdade de Desporto da Universidade do Porto

Rua Dr. Plácido Costa, 91 - 4200.450 Porto

Portugal

E-mail: ncortereal@fade.up.pt 


\section{REFERÊNCIAS}

1. Pastor, Y. Balaguer, I. \& Garcia-Merita, M. (1998). Una revisión sobre las variables de estilos de vida saludables. Revista de Psicologia de la Salud. 10, 1, 15-52.

2. Organização Mundial de Saúde (2002). Rapport sur la santé en Europe 2002. Genève (Suisse): Éditions OMS.

3. United States Department of Health and Human Services (1996). Physical activity and health: A report of the Surgeon General. United States Department of Health and Human Services, Centers for Disease Control and Prevention. Atlanta, GA: 1996.

4. Dishman, R. K. (1988). Exercise adherence. Champaign, IL: Human Kinetics.

5. Stephens, T., Jacobs, D. R., \& White, C. C. (1985). A descriptive epidemiology of leisure-time physical activity. Public Health Reports, 100, 147-158.

6. Luepker, R., Perry, C. Mckinley, S., Nader, P., Parcel, G., Stone, E., Webber, L., Elder, J., Feldman, H., Johnson, C., Kelder, S. \& Wu, M. (1996). Outcomes of a field trial to improve children's dietary patterns and physical activity: The child and adolescent trial for cardiovascular health (CATCH). JAMA, 275 (10), 768776.

7. Calfas, K., J., Sallis, J. F., Lovato, C. Y. \& Campbell, J. (1994). Physical a ctivity and its determinants before and after college graduation. Medicine, Exercise, Nutrition and Health, 3, 323-334.

8. Ruiz, F., Garcia, M. E. \& Gómez, M. (2005). Prática de actividad físico-deportiva de tiempo libre. In F. Ruiz, M. E. Garcia \& M. Gomez (Eds.), Hábitos físico-deportivos en centros escolares y universitarios. Madrid (Spain): Editorial Gymnos.

9. Sanz, E. (2005). La práctica físico-deportiva de tiempo libre en universitarios: Análisis y propuestas de mejora. Logroño (Spain): Universidade de La Rioja, Servicio de Publicaciones.

10. Buckworth, J. (2001). Exercise adherence in college students: Issues and preliminary results. Quest, 53, 335-345.

11. Caspersen, C. Nixon, P. \& Durant, R. (1998). Physical activity epidemiology applied to children and adolescents. Exercise and Sport Sciences Reviews, 26, 341-403.

12. Wallace, L. S., Buckworth, J., Kirby, T. E. \& Sherman, W. M. (2000). Characteristics of exercise behavior among college stu- 25. dents: Application of Social Cognitive Theory to predicting stage of change. Preventive Medicine, 31, 494-505.

13. Sallis, J. F. \& Mckenzie, T. L. (1991). Physical education's role in public health. Research Quarterly for Exercise and Sport, 62, 124-137.

14. Balaguer, I. (1999). Estilo de vida de los adolescentes de la comunidad valenciana: Un estudio de la socialización para la vida saludable. DGICYT (PB94-1555).
15. Montil, M. (2006). Determinantes de la conducta de la actividad física em población infantil. In A. Jiménez \& M. Montil (Eds.), Determinantes de la práctica de actividad física: Bases, fundamentos e aplicaciones (pp. 191-229). Madrid (Spain): Dykinson, S.L.

16. Tinsley, B. J., Holtgrave, D. R., Reise, S. P., Erdley, C. \& Cupp, R. G. (1995). Developmental status, gender, age, and self-reported decision-making influences on students' risky and preventive health behaviors. Health Education Quarterly, 22, 3244-3259.

17. Butcher, S. (1993). Socialization of adolescent girl's participation in physical activity. Adolescence, 18, 753-766.

18. Carratalá Deval, V., Garcia Ferriol, A. \& Carratalá Sánchez, E. (1998). Análisis de las diferencias por género e por grupo en los factores de los iguales relacionados con la práctica deportiva. Revista de Psicología del Deporte, 2 (7), 283-293.

19. Fox, K. (1992). Physical education and the development of self-esteem in children. In N. Armstrong (Ed.), Towards a National Curriculum-2: New Directions in physical education. Champaign, IL: Human Kinetics.

20. Wold, B. \& Anderssen, N. (1992). Health promotion aspects of family and peer influences on sport participation. International Journal of Sport Psychology, 23, 343-359.

21. Devis, J. (2000). Actividade física, deporte y salud. Alicante: Editorial Marfil, SA.

22. Corte-Real, N. (2006). Desporto, Saúde e Estilos de Vida: Diferentes olhares, objectivos e subjectivos, sobre os comportamentos dos adolescentes. Dissertação de doutoramento. Porto: Faculdade de Desporto da Universidade do Porto.

23. Conselho da Europa (1995). The significance of sport for society: Health, socialization, economy. Committee for the Development of Sport (CDDS): Holanda.

24. Sallis, J. F. (1995). A behavioural perspective on children's physical activity. In L. W. Y. Cheung \& J. B. Richmonds (Eds.), Child health, nutrition, and physical activity (pp.125139). Champaign, IL: Human Kinetics.

5. Matos, M., Simões, C., Carvalhosa, S., \& Canha, L. (2003). Saúde e estilos de vida em jovens portugueses: Estudo nacional da rede europeia HBSC/OMS (1996). Lisboa: Faculdade de Motricidade Humana, Universidade Técnica de Lisboa.

26. Sallis, J. F. (2000). Age-related decline in physical activity. Medicine and Science in Sports and Exercise, 32, 598-600.

27. Sallis, J. F., Prochaska, J., \& Taylor, W. (2000). A review of correlates of pshysycal activity of children and adolescents. Medicine Science in Sports and Exercise, 32 (5), 963-975. 